\title{
Subvalvular membranous aortic stenosis Results of surgical therapy
}

\author{
P. J. VAN DER SCHAAR, J. P. ROOS, AND J. ROHMER
}

From the Departments of Thoracic Surgery, Cardiology, and Paediatric Cardiology, Academisch Ziekenhuis, Leiden, The Netherlands

Subvalvular membranous aortic stenosis is usually accompanied by mild aortic insufficiency. This insufficiency is probably caused not by the valves but by the membrane. Resection of the membrane generally produces satisfactory results so far as the stenosis is concerned, and causes no significant aggravation of the insufficiency.

Subvalvular stenosis is caused by a diaphragm-like membrane. The stenosis is clinically manifested like any other form of aortic stenosis but is often associated with some aortic insufficiency. The occurrence of this aortic insufficiency, despite apparently normal valves and its course after the operation prompted us to begin this investigation.

One of the first detailed descriptions was that by Dilg (1883). Of the contemporary authors we may mention Morrow, Fort, Roberts, and Braunwald (1965), Braunwald, Goldblatt, Aygen, Rockoff, and Morrow (1966), as well as Hahn, Brom, and Nauta (1962), Hartman (1964), and Oakley and Hallidie-Smith (1967). The present paper discusses the diagnosis and operative results in 36 patients with subvalvular aortic stenosis, examined and treated by operation at the Academisch Ziekenhuis, Leiden, during the period 1958-66.

\section{CLINICAL ASPECTS}

AGE AND SEX A study by Hartman (1964) has shown that subvalvular membranous aortic stenosis occurs chiefly before the age of 20 . This could only be explained by the death of patients with this anomaly at an early age. Hartman's study also revealed a distinct female predominance of congenital valvular aortic stenosis, whereas subvalvular membranous aortic stenosis is about as frequent in males as in females. The male:female ratio in our material is $20: 16$. Our age distribution is as follows:

$$
\begin{array}{rrr}
0-5 & \text { years } & 2 \\
6-10 & \text { years } & 10 \\
11-15 & \text { years } & 10 \\
16-20 & \text { years } & 5 \\
<21 & \text { years } & 9
\end{array}
$$

SYMPTOMS The symptoms were often mild, especially at an early age, and consisted of fatigue and dyspnoea on exertion. Additional symptoms were dizziness, chest pain, and syncope. With children in particular it wasoften difficult to gain a clear impression of the symp-? toms. The occurrence of syncopes was generally con sistent with severe stenosis, but the symptoms werenot pathognomonic, nor was an asymptomatic aortico stenosis necessarily a harmless one.

PHYSICAL FINDINGS All patients had a coarse proto-s systolic murmur, which ranged in loudness from grade 2 (6) to grade 4 (6) and reached its maximum in then right second intercostal space; it was transmitted too the carotid arteries. A thrill was palpable at this site

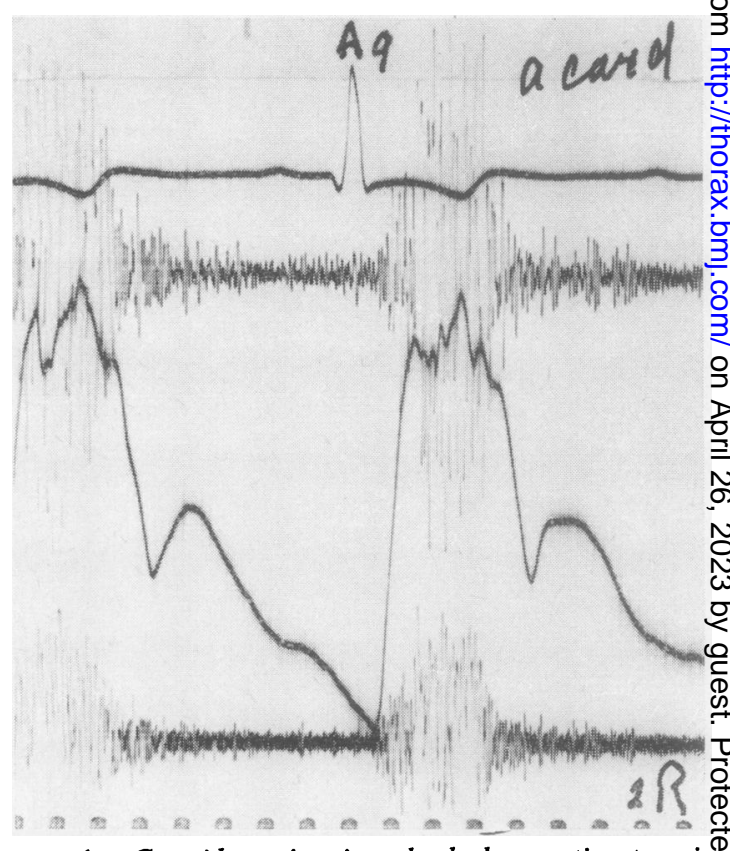

FIG. 1. Carotid tracing in subvalvular aortic stenosis尺 No ejection sound is present. 


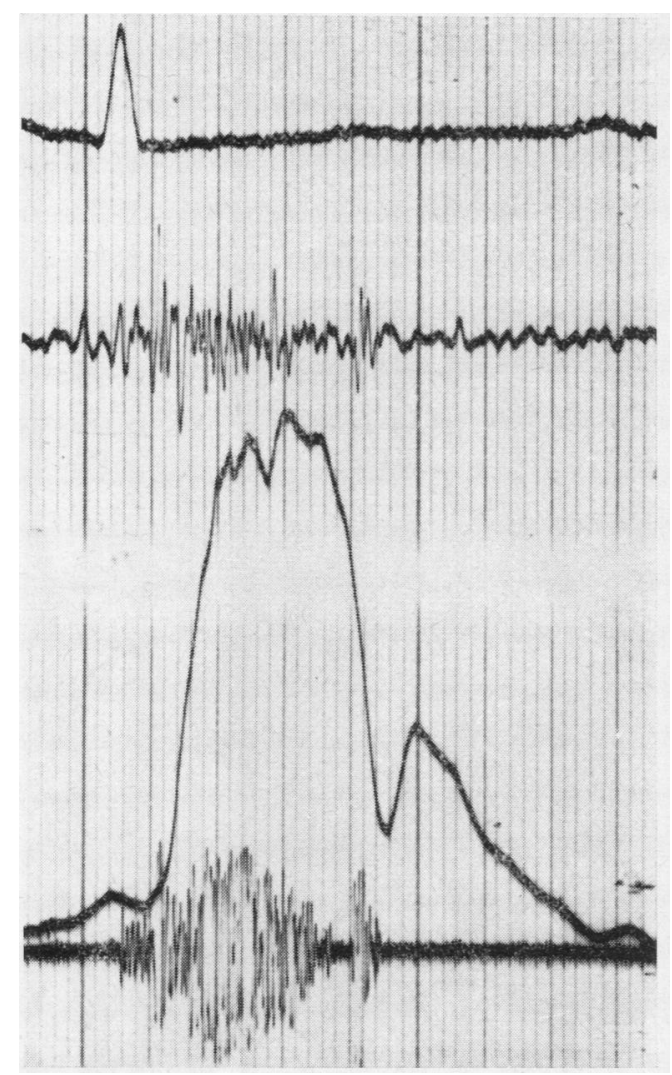

FIG. 2. Carotid tracing in valvular aortic stenosis. The ejection sound coincides with the start of the carotid upstroke.

in all patients. In none of the patients was an audible ejection sound found. A protodiastolic murmur was heard along the left sternal margin in 30 of the 36 patients. In view of the briefness of this murmur and the fact that the pulse pressure showed no or only a slight increase, it was assumed in all cases that the aortic insufficiency was not severe.

PHONOCARDIOGRAM (Figs 1-2) A systolic murmur was present in all cases. The onset of the murmur always coincided with the ascending leg of the carotid curve, and the murmur ended with a brief pause before the aortic component of the second sound. The first sound was visible on the phonocardiogram in about $50 \%$ of cases. The second sound was sometimes invisible in patients past the age of 20 . In this respect there was no unequivocal difference from valvular aortic stenosis.

A distinct difference concerned the ejection sound, which is nearly always present in valvular aortic stenosis unless the valves are sclerotic. The ejection sound occurs $0.02 \mathrm{sec}$. after the onset of ejection and is best recorded at the apex of the heart. Differentia- tion from the first sound is based on the presence or absence of the pause between the sound and the onset of the systolic murmur. There is never a pause between the ejection sound and the systolic murmur. A protodiastolic murmur was absent in six cases of subvalvular membranous aortic stenosis, but it usually is absent in young patients with valvular aortic stenosis. In a few instances, a fourth sound was recorded. As in the group of valvular aortic stenosis, the fourth sound was found mostly in cases of severe stenosis. The carotid curve of all patients showed oscillations at the top. A slow rise was not always present.

The relative ejection time was calculated with the aid of Meiners' (1958) diagram, which plots ejection time against cycle time. If the normal values of the relative ejection time are understood to be between $90 \%$ and $110 \%$, then the ejection time in all patients with subvalvular membranous aortic stenosis can be described as increased $(>110 \%)$. The majority of patients with a severe stenosis had a high a-peak in the apex cardiogram.

ELECTROCARDIOGRAM Although there are exceptions, the degree of left ventricular hypertrophy in the E.C.G. can be regarded as a reliable reflection of the severity of aortic stenosis.

None of the patients presented a normal E.C.G.; in only one case was the left ventricular hypertrophy mild, whereas in all other cases severe hypertrophy, with or without strain, was demonstrable in the E.C.G.

RADIOLOGY In all patients the anteroposterior chest radiographs showed a normal or only slightly increased heart size, but in all cases the left ventricle was slightly enlarged. Post-stenotic dilatation of the ascending aorta-virtually always in evidence in valvular aortic stenosis-is seldom observed in subvalvular membranous aortic stenosis.

Post-stenotic dilatation was absent in 32 of our 36 patients. None of the patients had sclerotic valves.

ANGIOCARDIOGRAPHY In order to visualize the stenosis, contrast medium must be injected into the left ventricle. A few millimetres below the valves there is a filling defect, which is usually most conspicuous on AP radiographs. The filling defect is usually narrow and fully visible only during systole. The ascending aorta is seldom dilated.

Figure 3 shows an exposure made during systole, which clearly reveals the (this time rather broad) filling defect.

DIFFERENTIAL DIAGNOSIS The principal feature in the differential diagnosis between valvular and subvalvular aortic stenosis is the faot that no ejection sound is present in the latter. The presence of calcified valves is an argument in favour of valvular aortic stenosis, although young patients with valvular aortic stenosis usually have no calcified valves.

The difference between valvular and subvalvular aontic stenosis can be established with centainty by 


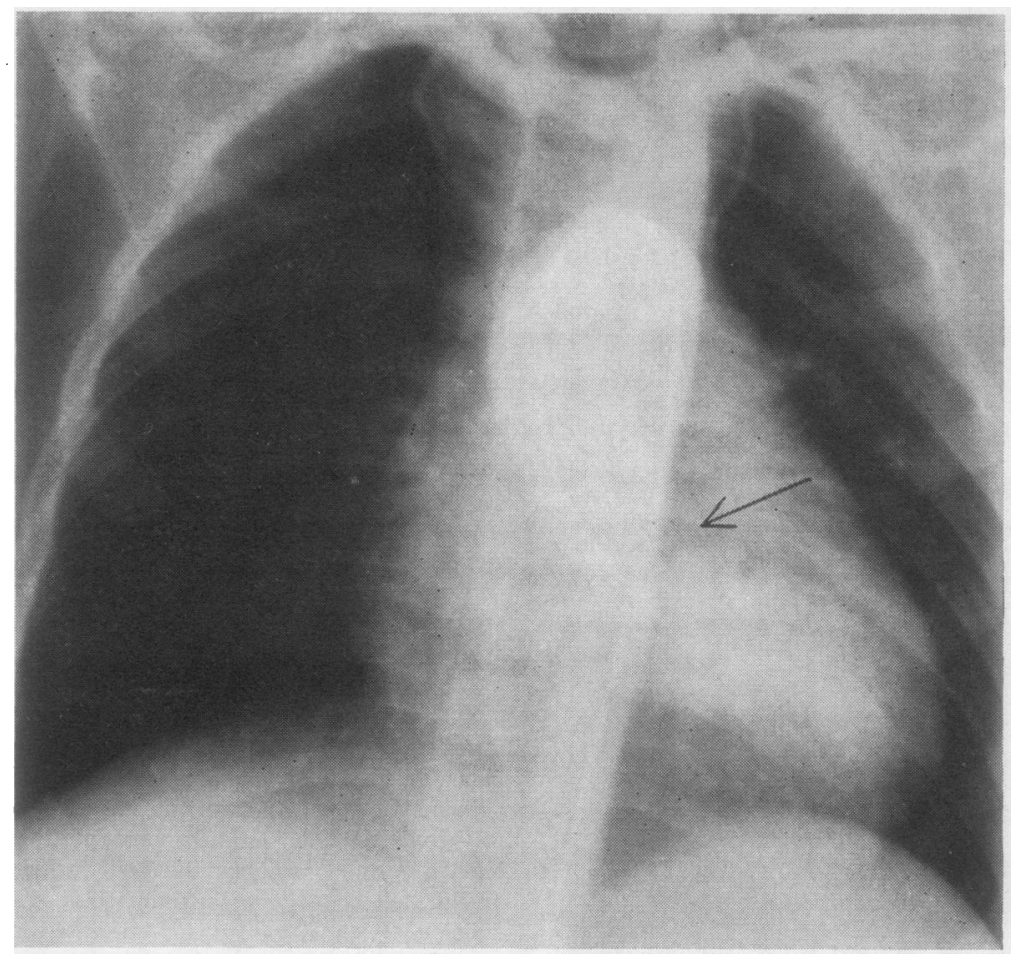

FIG. 3. Frontal position in systole. Angiocardiogram of the left ventricle. A filling defect is visible just below the aortic valves.

means of selective angiocardiography and also during catheterization while the catheter is slowly withdrawn from the left ventricle towards the aorta.

INDICATION FOR OPERATION The indication for operation is generally determined by a combination of (1) symptoms (ranging from fatigue to syncope); (2) E.C.G. evidence of left ventricular hypertrophy ; and (3) a pressure gradient of some $70 \mathrm{~mm}$. $\mathrm{Hg}$ or more.

However, it is not always easy to choose the right time for surgery in these cases, particularly when the symptoms are not severe. The operation might well be postponed in cases with only slight hypertrophy of the left ventricle and a small pressure gradient, for surgical techniques are likely to be funther perfected in the near future.

PROCEDURE The first eight patients were treated by a blind technique or under hypothermia. In the next cases, extracorporeal circulation was used. Our present procedure is the following. A median sternotomy is followed by drainage of the right atrium with the aid of a wide cannula; other cannulae are inserted into the aorta and the left ventricle. The aorta is clamped and transversely incised about $3 \mathrm{~cm}$. distal to the annulus. Some patients were given coronary perfusion at this stage, but in view of the relatively short duration of the intervention this might not be necessary. The cusps are then carefully pushed aside.
The membrane is localized a few millimetres below the proximal insertion of the cusps. The perforation in the membrane (diaphragm) is not always centralo but may be excentric. In resection of the membrane, the topography of the aortic leaflet of the mitral valve and the bundle of His must be borne in mind. The 3 smallest part of the anterior leaflet lies below the noncoronary cusp, while the remainder is below the left윽 cusp. The bundle lies for the most part below the commissure between the right coronary and the non-윽 coronary cusps. The part that can be safely resected $D$ lies below the right coronary cusp, between its centre음 and the commissure between the right and left cusps (Figs 4 and 5).

Pressures in the aorta and left ventricle are measured before starting extracorporeal circulation and before closing the thorax.

Of the other techniques also used, only those willo be mentioned that were applied with extracorporealo circulation: incision of the membrane between the $\frac{\bar{\Phi}}{\mathscr{D}}$ left and right coronary cusps; incision with resection? of part of the membrane; resection of pant of the 0 membrane with incision of the myocardium.

In cases in which a muscular stenosis was suspected, $\stackrel{\vec{D}}{\vec{D}}$ incision of the muscular ventricular septum was $\frac{\rho}{\Phi}$ carried out as well ; in one case, a muscle fragment? was punched out at this site.

The above operations were sometimes combined with dilatation. 


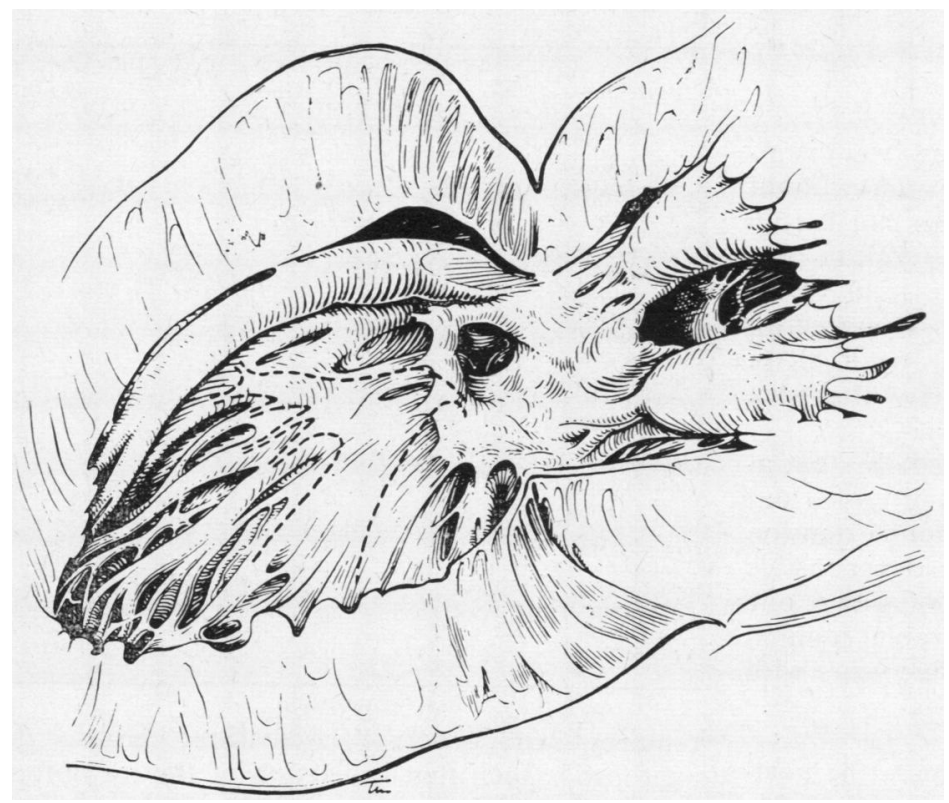

FIG. 4. Drawing from a necropsy specimen. Transsection of the left ventricle. Dotted line is the projection of the left bundle branch.

FIG. 5. Same necropsy specimen as in Fig. 4. Aorta opened.

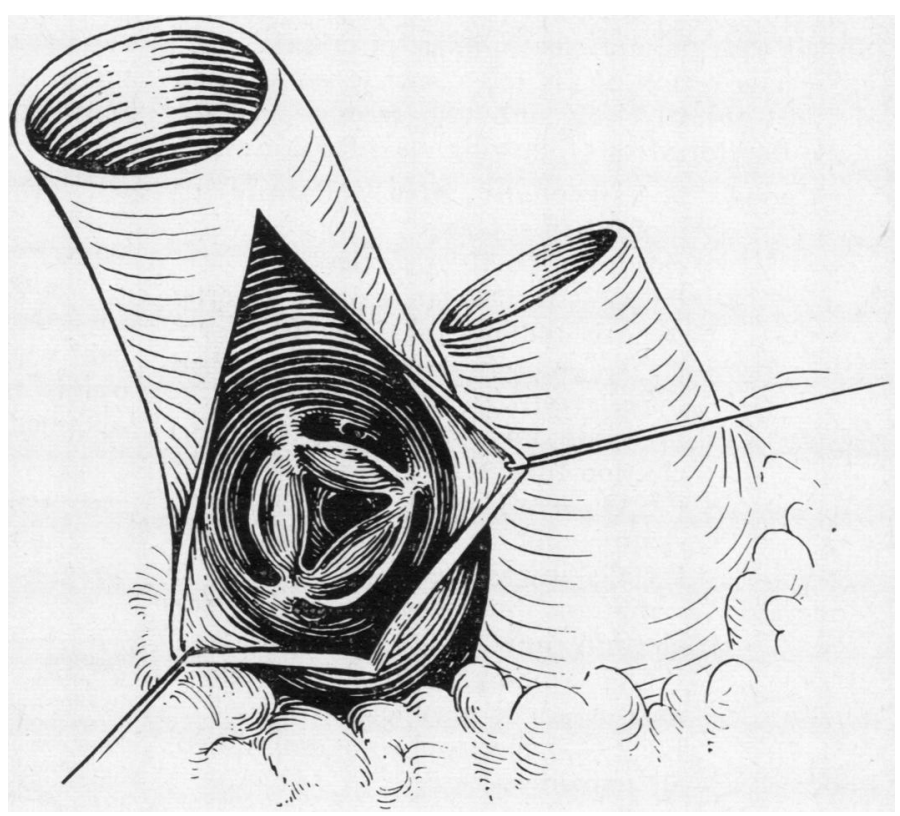

\section{OPERATIVE RESULTS}

We specifically considered the following features:

1. Survival ;

2. Late results with reference to procedure, residual stenosis, aortic insufficiency, and validity (i.e., physical fitness);
3. The relation between pre-operative and postoperative aortic insufficiency;

4. The relation between aortic insufficiency and surgical procedure ;

5. The relation between aortic insufficiency and abnormal valves ; 
6. The relation between pre-operative and postoperative pressure gradients and the ultimate result.

SURVIVAL In evaluating these cases, we distinguished between operations with and without extracorporeal circulation. The results can hardly be compared, because the earlier surgical procedure is decidedly inferior. Of the total of 36 patients treated by operation, 28 were operated on using extracorporeal circulation. Two of these patients died during or immediately after the operation; two died later.

In the group of patients treated by extracorporeal circulation we had a mortality of 4 out of 28 ; post-operative complications (tension pneumothorax and haemorrhage) were responsible for two of these deaths. Of the remaining two, one died after 11 months with considerable residual stenosis, whilst the other died after five years with severe aortic insufficiency.

LATE RESUlTS It is difficult to evaluate the postoperative condition correctly. There is no reliable standard, and evaluation of results must be accomplished with the aid of a number of criteria.

Catheterization of the left ventricle was carried out post-operatively in only two cases.

We developed the following classification:

Very good: no symptoms after follow-up of more than a year;

ejection time $105 \%$ or less ;

P.C.G.-at worst slight aortic stenosis and/or aortic insufficiency;

E.C.G.-unmistakably diminished hypertrophy.

Good: no symptoms ; ejection time $110 \%$ or less ;

P.C.G. - mild-to-moderate aortic stenosis and/or aortic insufficiency; E.C.G.-hypertrophy diminished.

Moderate: symptoms diminished or stationary ; ejection time $110-115 \%$;

P.C.G.-moderate aortic stenosis and/or aortic insufficiency ;

E.C.G.-hypertrophy not diminished.

Poor: all remaining cases.

The two last groups (moderate and poor) were taken together under the heading 'unsatisfactory'.

The procedures used were classified as shown in Table I. Although the groups of cases were relatively small, it seems justifiable to conclude that resection combined with extracorporeal circulation yields good results. It must also be concluded that operation for this condition
T A B L E I

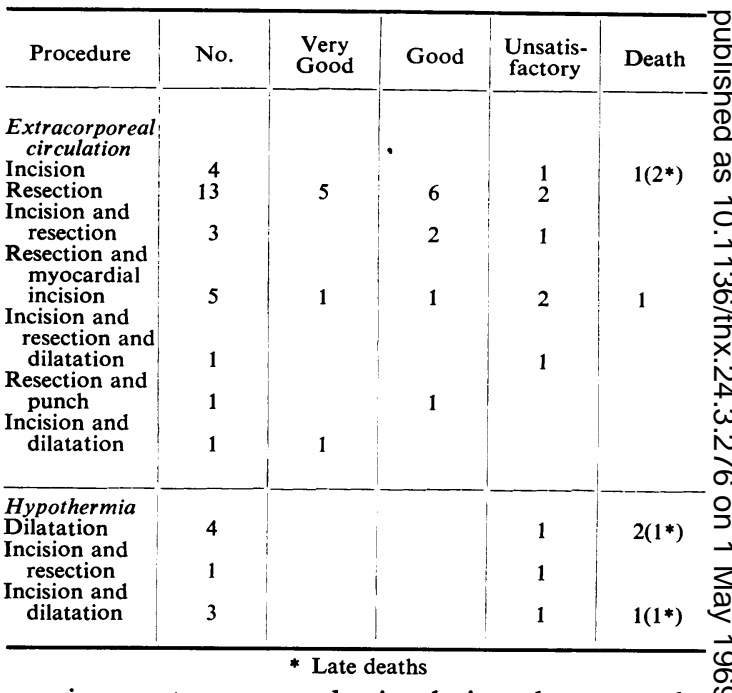

requires extracorporeal circulation because the anatomy is such that inspection of the membrane is indispensable.

PRE-OPERATIVE AND POST-OPERATIVE AORTIC INSUFFICIENCY It was difficult to gain a clear impres- $\mathbb{D}$ sion of the severity of aortic insufficiency, because $\vec{F}$ the P.C.G. findings were the only data available for this purpose. No post-operative angiocardiograms were available because only two patients underwent catheterization after the operation.

Changes in the murmur after operation warrant $\vec{\partial}$ some conclusions. It is likewise possible to establish whether aortic insufficiency (A.I.) did not $\dot{\circ}$ occur until after the operation. The results 3 . obtained are presented in Table II. In many cases,

T A B L E I I

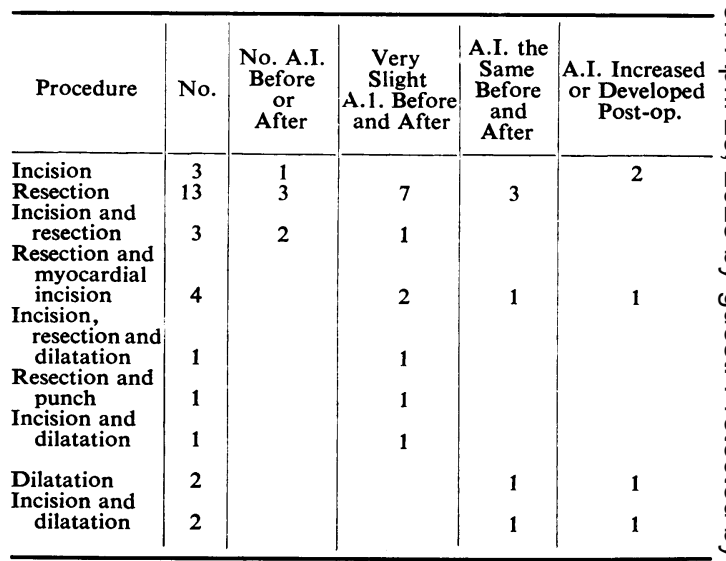

A.I. $=$ aortic insufficiency.

(1)

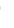

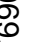


A.I. already existed before operation, and in the majority of these there was no post-operative aggravation.

RELATION BETWEEN AORTIC INSUFFICIENCY AND SURGICAL PROCEDURE Table II also indicates that the surgical procedure exerts an influence on the occurrence or aggravation of A.I. The procedure most frequently used (resection) did not influence A.I. in any of these cases. The few cases of postoperative A.I. concerned incision and resection with incision of the left ventricular myocardium, and two cases of operation under hypothermia. In view of the lack of time and consequently limited possibility of pre-operative study, the lastmentioned two cases are not surprising. It is not clear, however, why A.I. occurred following the other three operations.

RELATION BETWEEN AORTIC INSUFFICIENCY AND ABNORMAL VALVES Valves were found to be normal in all cases except two. In these two cases, bicuspid valves were found but there was no significant A.I. in these patients. In view of the findings it seems unlikely that the valves as such might give rise to A.I.

RELATION BETWEEN PRESSURE GRADIENT AND OPERATIVE RESULT Evaluation of the pre- and post-operative pressure gradients is a dubious undertaking because it is virtually impossible to ensure constant conditions of determination. The difference might be overcome to some extent by expressing the gradient in per cent of the left ventricular pressure. However, records of absolute pressures were available in only nine cases. In the other cases, only the gradient was noted during the operation. This is why groups 'very good' and 'good' were taken together, as were groups 'moderate' and 'poor'.

\begin{tabular}{|c|c|c|c|c|c|}
\hline & Verv Good and Good & ood & \multicolumn{3}{|c|}{ Moderate and $\mathbf{P}$} \\
\hline Gradient & $\begin{array}{c}\text { Before } \\
20 \% \\
33 \% \\
44 \% \\
53 \% \\
45 \%\end{array}$ & $\begin{array}{r}\text { After } \\
0 \% \\
7 \% \\
9 \% \\
10 \% \\
24 \%\end{array}$ & Gradient & $\begin{array}{c}\text { Before } \\
45 \% \\
20 \% \\
35 \% \\
41 \%\end{array}$ & $\begin{array}{l}\text { After } \\
48 \% \\
0 \% \\
21 \% \\
0 \%\end{array}$ \\
\hline
\end{tabular}

These figures only warrant the conclusion that it is possible to obtain fair results in spite of a high pre-operative gradient and that, on the other hand, disappearance of the gradient (on the operating table immediately after surgery) does not necessarily mean a successful operation.

\section{DISCUSSION}

A feature of subvalvular membranous aortic stenosis is that it is so often associated with some aortic insufficiency. Superficially this may produce the impression that any operation for this condition results in aortic insufficiency, and this impression is enhanced when different physicians examine the patient before and after the operation.

The insufficiency has little to do with the valves per se, for these are nearly always normal. Consequently we suggest that the cause of the insufficiency is the membrane; but the exact role of the membrane is not explicable.

In this context we suggest a few possibilities, viz. :

1. The membrane causes the valves to assume an abnormal position in relation to each other, e.g., due to accretion to one or several other valves as a result of torsion of the annulus. However, inspection of surgical and anatomical specimens has revealed no such situation.

2. The membrane mechanically prevents closure of the valves by virtue of its situation immediately below the cusps. Consequently the latter cannot fill sufficiently, or not in the appropriate way, to close the valve with adequate force. This explanation is not entirely satisfactory.

3. Subvalvular stenosis may be responsible for the insufficiency in that it creates a pressure baffle between the intraventricular pressure and the pressure above the valves. This is why it takes longer for the pressure gradient to build up, and during this period the valves are not sufficiently expanded.

Oakley and Hallidie-Smith (1967) suggested that the early diastolic murmur begins because blood flows back through the valve and is maintained (after valve closure) by blood flowing back through the stenosis. This theory seems possible. The valves are less mobile than in non-calcified valvular aortic stenosis, as demonstrated by the absence of an ejection sound. However, this must not be ascribed to the valve per se, but is due to the pressure baffle imposed by the subvalvular obstruction.

Meanwhile it is justifiable to conclude that the operation, as we are now performing it, has little influence on aortic insufficiency unless something is done to the annulus or part of the membrane is left intact which prevents one of the valves from closing completely.

Consequently it might be useful to consider whether resection of the membrane ought not to be preferred to partial resection. This would also reduce the residual stenosis which (in a mild degree) remains in a considerable number of cases. In other words, the insufficiency will probably be less marked as the stenosing structure is more widely resected. 
We feel justified in stating that incision alone yields poor results, also in terms of aortic insufficiency. Operations under hypothermia, without extracorporeal circulation, are not justified in view of the complex anatomy.

Although good operative results have been obtained even in patients with a high pressure gradient, it is nevertheless better not to postpone operation. The severity of symptoms is not a yardstick of the severity of the condition. Sudden death occurs in cases with only mild symptoms.

As in other forms of aortic stenosis, the pressure gradient and severity of the E.C.G. changes are the decisive factors in determining operation. We emphasize that the natural course of the condition is often unfavourable even in children.

\section{REFERENCES}

Braunwald, E., Goldblatt, A., Aygen, M. D., Rockoff, S. D., and Morrow, A. G. (1966). Congenital aortic stenosis. Circulation, 27, 426.

Dilg, J. (1883). Ein Beitrag zur Kenntniss seltener Herzanomalien im Anschluss an einen Fall von angeborner linksseitiger Conusim Anschluss Virchows Arch. path. Anat., 91, 193.

Hahn, C., Brom, A. G., and Nauta, J. (1962). Chirurgie du Coeur, p. 97. Bibliotheca Cardiologica, fasc. 12-Fortschritte der Kardiologie, Vol. 3.

Hartman, H. (1964). Fonocardiografie en polscurven. Thesis, Leiden.

Meiners, S. (1958). Messmethoden zur Analyse der Herz-und Kreislaufdynamik. In Kreislaufmessungen: Vorträge des ersten Freiburger Colloquiums, 1958, ed. Weber, A., and Blumberger, K., p. 84. Bandschewski, Munich.

Morrow, A. G., Fort, L., Roberts, W. C., and Braunwald, E. (1965). Discrete subaortic stenosis complicated by aortic valvular regurgitation. Circulation, 31, 163.

Oakley, C. M., and Hallidie-Smith, K. A. (1967). Assessment of site and severity in congenital aortic stenosis. Brit. Heart J., 29, 367. 